\title{
One-stage Posterior Approach in the Treatment of Consecutive Multi-segment Thoracic Tuberculosis with Kyphosis
}

\author{
Nanzhe ZHONG*, Jinhai KONG*, Zhengwang SUN, Ming QIAN, Tielong LIU, Jianru XIAO \\ Second Military Medical University, Changzheng Hospital, Department of Orthopedic Oncology, Shanghai, China \\ *Nanzhe ZHONG and Jinhai KONG are the first authors.
}

\section{ABSTRACT}

AIM: To evaluate the clinical efficacy of the one-stage posterior approach in treating consecutive multiple-segment thoracic tuberculosis with kyphosis.

MATERIAL and METHODS: A retrospective study was performed. The data of 22 patients with consecutive multi-level thoracic tuberculosis and kyphosis who underwent the one-stage posterior approach of debridement, bone grafting, drainage and pedicle screws fixation were collected. The kyphotic angle was $61.6^{\circ} \pm 3.1^{\circ}$ pre-operatively. The neurologic status based on American Spinal Injury Association (ASIA) scoring was A in 5 cases, B in 4 cases, $C$ in 9 cases, D in 3 cases and $E$ in 1 case.

RESULTS: The average follow-up period was $43.4 \pm 5.0$ months. The kyphotic angle was $19.8^{\circ} \pm 0.7^{\circ}$ after operation $(p<0.01$ ), and $21.9^{\circ} \pm 1.2^{\circ}$ at the last visit $(p<0.01)$. No neurological deterioration was observed in any patients after surgery. A significant difference in ASIA score was detected when the state before the operation and the last visit was compared $(p<0.01)$. There was no recurrent paravertebral abscess of thoracic tuberculosis in any of these cases.

CONCLUSION: The one-stage posterior approach of debridement and drainage is a feasible surgical option for consecutive multisegment thoracic tuberculosis with kyphosis. It can achieve debridement, decompression, and stabilization simultaneously.

KEYWORDS: Kyphosis, Multi-segment, Surgery, Thoracic tuberculosis

\section{INTRODUCTION}

$\mathrm{T}$ Thoracic tuberculosis is probably secondary to pulmonary tuberculosis. The destruction of vertebrae may lead to instability, kyphosis, and neural deficiency of the spine (12). The characteristics of consecutive multi-level thoracic tuberculosis include indolent course and long-term invasion. Most patients have relapsed symptoms of tuberculosis due to irregular anti-tuberculosis treatment and appearance of drug-resistant strains of tuberculosis, and are characterized by marked neurological symptoms, back pain and spinal deformities (3). A few of the patients may have sensation and movement disorders, disturbance of urination and defecation, and even disability $(6,9)$. Besides, concurrent pulmonary infection could cause high mortality among these patients (4).
As a matter of fact, the pendulum of surgical options for thoracic spinal tuberculosis periodically vacillates between the anterior approach, the posterior approach and the combined posterior-anterior approach $(1,10,13,15)$. It has been suggested that the selection of the surgical approach often requires making trade-offs between the advantages and disadvantages of the above-mentioned choices, depending on their own indications (14). As for the cases with multisegment spinal tuberculosis, a similar controversy also exists $(4,7)$, and the operation procedure should be individualized with consideration of the location and extension of the lesion and also the neurological condition of the patient.

To our knowledge, there are few studies reporting the efficacy of a single-stage posterior procedure of debridement and 
reconstruction on consecutive multi-segment thoracic spinal tuberculosis with kyphosis. Therefore, we present the clinical data of 22 patients with consecutive multi-segment thoracic spinal tuberculosis and kyphosis who were treated with onestage posterior procedure of debridement, bone grafting or iliac crest bone with titanium meshes combined with internal fixation. In addition, the outcome and effectiveness of this procedure were discussed.

\section{MATERIAL and METHODS}

\section{Patient Cohort and Radiological Studies}

From May 2008 to November 2014, the clinical data of 22 patients were reviewed. These patients were diagnosed as consecutive multi-segment thoracic spinal tuberculosis with kyphosis (average Cobb's angle $=61.6 \pm 3.1^{\circ}$ ) at our institution (Table I). The ethical approval by our institutional review board was not required for this retrospective study.

Roentgenogram, computed tomography (CT) and magnetic resonance imaging (MRI) of the thoracic spine were performed on all the patients. This cohort was composed of 14 male and 8 female patients with a mean age of 45.5 years (range 1976 years). All cases had featured symptoms of tuberculosis, including low fever and night-sweat. Besides, 17 cases had weight loss and 20 cases had back pain. It was noted that all had a history of tuberculosis (Table I). Physical examination showed tenderness and percussion pain in the thoracic vertebrae in 22 cases, rigidity of back muscle due to spasm in 15 cases, an ellipse mass on back on palpation in one case, sensory deprivation in the saddle area with loss of anal reflex in 9 cases, and knee jerk hyperreflexia in one case. The neurological status was graded according to the American Spinal Injury Association (ASIA) classification. There were 21 cases of paraplegia, including complete paralysis in 5 cases ( 5 with ASIA A), incomplete paralysis in 16 cases (4 with ASIA B, 9 with ASIA C, 3 with ASIA D) (Table II). The erythrocyte sedimentation rate (ESR) ranged from 46 to $97 \mathrm{~mm} / \mathrm{h}$ (median: $68 \mathrm{~mm} / \mathrm{h}$ ), with 15 cases exceeding $60 \mathrm{~mm} / \mathrm{h}$. Pulmonary dysfunction was found in 11 cases, and hypoproteinemia in 16 cases (Table I). Active pulmonary tuberculosis was excluded in all cases.

Based on the evaluations (thoracic anteroposterior and lateral position X-rays, CT and MRI), destruction of the vertebra and intervertebral discs were found in all patients, and spinal cord compression was found in 17 cases. The number of involved segments was 2 in 3 cases, 3 in 13 cases, 4 in 3 cases, 5 in 2 cases, and 6 in 1 case. Nineteen cases had paravertebral abscess ( 8 cases on the left side; 7 cases on the right side; 4 cases on both sides). Five cases had destruction of costal bones, including three cases on the left side (T5, T8, and T9 separately) and 2 cases on the right (T6, T7 respectively). Four cases had lesions of the appendix of vertebra. The preoperative Cobb's angle of kyphotic deformity ranged from $40^{\circ}$ to $105^{\circ}$, with an average of $61.6^{\circ} \pm 3.1^{\circ}$ (Table I).

\section{Treatment Strategies}

Radiological examinations (X-rays, CT and MRI) were performed preoperatively to explore the extension of vertebral destruction and paravertebral abscess, the existence of sequestrums, soft tissue calcification, diseased appendix, and the integrity of the pedicles that would be implanted with pedicle screws. Before the procedure, all patients were prescribed isoniazid $(\mathrm{INH})(5 \mathrm{mg} / \mathrm{kg})$ and rifampicin $(10 \mathrm{mg} / \mathrm{kg})$, pyrazinamide $(25 \mathrm{mg} / \mathrm{kg})$ and ethambutol $(15 \mathrm{mg} / \mathrm{kg})$ for at least two weeks, until the ESR decreased below $40 \mathrm{~mm} / \mathrm{h}$ and the temperature reached a level near normal. Exceptionally, for those patients who had neurological worsening to ASIA A or ASIA B level in a very short time, the surgery was performed as soon as possible to achieve early decompression. Instead, before operation, conservative therapy with a duration of no more than one week would be administered to stabilize the general condition and control the infection as much as possible.

Table I: Demographic Data of the Patients

\begin{tabular}{|c|c|}
\hline Parameters & $\mathbf{n}$ \\
\hline Gender (M/F) & $14 / 8$ \\
\hline Mean age in years (range) & $45.5(19-76)$ \\
\hline \multicolumn{2}{|l|}{ History of pulmonary tuberculosis (\%) } \\
\hline Pulmonary tuberculosis & $22(100 \%)$ \\
\hline Tuberculosis of pleura and pleural effusion & $1(4.5 \%)$ \\
\hline Tuberculosis of lymph nodes & $2(9.1 \%)$ \\
\hline $\begin{array}{l}\text { Tuberculosis of femoral articulation and } \\
\text { abscess in iliac fossa }\end{array}$ & $1(4.5 \%)$ \\
\hline Renal tuberculosis & $1(4.5 \%)$ \\
\hline Gastrointestinal tuberculosis & $6(27.3 \%)$ \\
\hline \multicolumn{2}{|l|}{ Incidence of Co-morbidities (\%) } \\
\hline None & $9(40.9 \%)$ \\
\hline Pulmonary dysfunction & $11(50.0 \%)$ \\
\hline Hypoproteinemia & $16(72.7 \%)$ \\
\hline \multicolumn{2}{|l|}{ Number of affected vertebrae (\%) } \\
\hline 2 segments & $3(13.6 \%)$ \\
\hline 3 segments & $13(59.1 \%)$ \\
\hline 4 segments & $3(13.6 \%)$ \\
\hline 5 segments & $2(9.1 \%)$ \\
\hline 6 segments & $1(4.5 \%)$ \\
\hline
\end{tabular}

\section{Preoperative Complications}

Paravertebral abscess (left/right/both) $19(8 / 7 / 4)$

Destruction of costal bones (left/right) $5(3 / 2)$

Destruction of the appendix of vertebrae 4

Mean preoperative kyphosis angle (range) $\quad 61.6 \pm 3.1^{\circ}$

M: Male, F: Female. 
Table II: Preoperative and Final Follow-Up Neurological Function $(p<0.05)$

\begin{tabular}{ccccccc}
\hline \multirow{2}{*}{$\begin{array}{c}\text { ASIA score } \\
\text { on admission }\end{array}$} & Number & \multicolumn{5}{c}{ ASIA score at final follow-up } \\
\cline { 2 - 7 } & & A & B & C & D & E \\
\hline A & 5 & 1 & 0 & 1 & 2 & 1 \\
\hline B & 4 & 0 & 0 & 2 & 1 & 1 \\
\hline C & 9 & 0 & 0 & 1 & 3 & 5 \\
\hline D & 3 & 0 & 0 & 0 & 0 & 3 \\
\hline E & 1 & 0 & 0 & 0 & 0 & 1 \\
\hline
\end{tabular}

ASIA: American Spinal Injury Association.

\section{Surgical Technique}

All patients were in the prone position after general anesthesia. The lamina, transverse processes, costotransverse and facet joints were exposed through a posterior midline incision. Then, screws were inserted respectively at pedicles of the healthy vertebra adjacent to the involved vertebra. After the placement of pedicle screws was confirmed by C-arm fluoroscopy, a contoured rod referring to the physiological kyphotic angle was placed to stablize the spine temporarily. Before laminectomy or hemilaminectomy and exposing the spinal roots, the degree of vertebral destruction was ascertained. If paraplegia was induced by spinal cord compression, the debridement of the foci would be carried out around the spinal canal for decompression and methylprednisolone was infused intravenously in all cases at $30 \mathrm{mg} / \mathrm{kg}$ in thirty minutes preceded the decompression. For the angular kyphosis deformity with high bone density, we used a drill instead of bone-chisel and dribbled ice saline constantly on the bone to avoid nerve root injury by overheated bone. Additionally, somatosensory-evoked potential monitoring was used to examine the activity of lower limbs at each step, especially during the decompression for detecting intraoperative neural damage. A posterior vertebral column resection (PVCR) technique was applied for spinal column resection to remove the posterior elements of the spinous processes, laminae, facet joints and transverse processes. This method could facilitate the correction of rigid deformities while reducing the risk of spinal cord over-stretch or kinking during osteotomy. Then, discectomy was performed and the abscess was completely evacuated. During this process, the pus was drained through negative pressure suction and the anterior longitudinal ligament, the thickened periosteum or abscess wall were bluntly dissected for the isolation of involved vertebrae. Following the preliminary debridement, the corpectomy was performed and the ring-like scar tissue was thoroughly resected so as to achieve complete decompression. In order to improve the debridement of the surrounding abscess, the granulation tissue on the abscess wall, the caseous tissue, the sequestrum and the granulation tissue were carefully removed. Furthermore, to evacuate the tubercular foci that had spread along the intercostal space, long and curved curettes of various arcs were used. After the decompression, the adjacent healthy vertebrae were distracted to insert bone graft or titanium mesh cages into the interbody. Among our cases, 15 patients received autogenic bone graft, and 7 patients received bone graft fusion with titanium mesh. During the posterior placement of grafts after osteotomy, it was necessary to sacrifice one or two adjacent nerve roots of one side to ensure better exposure, and provide enough space for the insertion of the titanium mesh or cage. However, this did not lead to obvious neurological problems. Subsequently, deformity correction and stabilization were ensured by installing permanent rods. $0.3 \mathrm{~g}$ isoniazid and/or 1-2 $\mathrm{g}$ streptomycin were placed into the intervertebral area during the operation.

\section{Postoperative Procedure and Follow-up}

Vital signs were monitored closely, and other symptomatic treatments were adopted. Postoperative chemotherapy with $\mathrm{INH}$ (0.3 g qd po), rifampicin (0.45 g qd im), ethambutol (0.75 $\mathrm{g}$ qd im), levofloxacin ( $0.75 \mathrm{~g}$ bid iv) and streptomycin $(75 \mathrm{mg}$ qd im) was given for six months, followed by rifampicin/INH/ streptomycin/levofloxacin/pyrazinamide (75 mg qd im) for another 6 months. The whole course of the treatment would last for one and a half years at least. The drainage tube would be removed if the drainage flow was less than $50 \mathrm{~mL} / 24 \mathrm{~h}$ and the lungs expanded well after one-day clipping of the tube. The spine was immobilized with an orthosis for six months until bony fusion was achieved. Hematological parameters, ESR, C-reactive protein (CRP), liver function tests were monitored and radiographic examinations (X-rays) were performed at the $3^{\text {rd }}$ month after surgery, then every 6 months to monitor the side effects of drugs, and the bony fusion until two years after surgery.

\section{Statistics Analysis}

All statistical analysis was performed with the SPSS 18.0 analysis software. To compare the pre- and postoperative, clinical and radiological data, the Paired Sample t-test was used, and a $p$ value $<0.05$ was considered statistically significant.

\section{RESULTS}

The average duration of surgery was $340.4 \pm 16.7$ minutes, and the mean blood loss was $2238.6 \pm 102.3 \mathrm{ml}$ during 
surgery (Table III). Two cases had stretch injury of nerves and recovered after application of neurotrophic drugs and three-week hyperbaric oxygenation. One case had pleural membrane laceration, which was sutured during operation without any complication occurring after operation. Chyle leakage was detected in one case postoperatively, and resolved after mediastinum drainage for about two weeks. Two cases had dural sac rupture and were repaired with artificial dura. Postoperatively, two cases had numbness in the lower limbs, and were alleviated by rehabilitation training two weeks later. There were no injuries of large blood vessels or nerves, deep wound infection or sinus formation. All incisions were healed by first intention. In all cases, the symptoms of low fever and night-sweats disappeared in two weeks. The back pain in all cases was eased after the operation, with the longest duration for less than six months. No neurological deterioration or adverse events of drugs was observed in any patient after surgery. Most patients with spinal cord affection had recovered at the last follow-up (Table II), except for 1 case with ASIA A and 1 case with ASIA $C$ who remained unchanged $(p<0.01)$. The follow-up period ranged from 24 to 108 months, with an average of $43.4 \pm 5.0$ months. The ESR decreased from $67.7 \pm 3.1 \mathrm{~mm} / \mathrm{h}$ to $27.5 \pm 1.4 \mathrm{~mm} / \mathrm{h}$ post-operatively $(p<0.01)$, and further decreased to $15.2 \pm 1.0 \mathrm{~mm} / \mathrm{h}$ at the last followup $(p<0.01)$. The kyphotic angle reduced from $61.6 \pm 3.1^{\circ}$ pre-operatively to $19.8 \pm 0.7^{\circ}$ after operation $(p<0.01)$, and to $21.9 \pm 1.2^{\circ}(p<0.01)$ at the final follow-up. The correction rate of kyphosis was $67.9 \%$, and there was a mean correction loss of $2.0 \pm 0.9^{\circ}$ at the last visit (Table IV). The radiological data of an illustrative case is presented in Figure 1A-E. Bone fusion was achieved in all patients at the last follow-up, with the fusion time ranging from 8 to 12 months. There was no recurrence of paravertebral abscess of tuberculosis in any case.

Table III: Clinical and Surgical Details of the Patient Group

\begin{tabular}{|c|c|c|c|c|c|c|c|c|}
\hline No & Sex & $\begin{array}{c}\text { Age } \\
\text { (years) }\end{array}$ & $\begin{array}{c}\text { Recurrent time } \\
\text { (months) }\end{array}$ & $\begin{array}{c}\text { Operation time } \\
\text { (minutes) }\end{array}$ & $\begin{array}{c}\text { Blood loss } \\
(\mathrm{ml})\end{array}$ & $\begin{array}{c}\text { Transfusion } \\
(\mathrm{ml})\end{array}$ & $\begin{array}{c}\text { Drainage } \\
(\mathrm{ml})\end{array}$ & $\begin{array}{c}\text { Extubation time } \\
\text { (days) }\end{array}$ \\
\hline 1 & $M$ & 44 & 71 & 355 & 2110 & 1700 & 240 & 13 \\
\hline 2 & $M$ & 22 & 35 & 369 & 3100 & 2500 & 150 & 11 \\
\hline 3 & $M$ & 26 & 17 & 297 & 2600 & 1900 & 80 & 10 \\
\hline 4 & $\mathrm{M}$ & 22 & 23 & 357 & 2250 & 1800 & 270 & 15 \\
\hline 5 & $\mathrm{M}$ & 20 & 11 & 360 & 3150 & 3000 & 290 & 12 \\
\hline 6 & $\mathrm{~F}$ & 67 & 19 & 265 & 2700 & 2500 & 160 & 10 \\
\hline 7 & $\mathrm{~F}$ & 54 & 13 & 357 & 2050 & 2000 & 190 & 11 \\
\hline 8 & $\mathrm{~F}$ & 66 & 27 & 275 & 2970 & 2400 & 210 & 16 \\
\hline 9 & $M$ & 64 & 18 & 316 & 2160 & 1900 & 90 & 9 \\
\hline 10 & $M$ & 65 & 46 & 375 & 2350 & 2500 & 85 & 7 \\
\hline 11 & $\mathrm{~F}$ & 62 & 32 & 269 & 2270 & 2000 & 65 & 8 \\
\hline 12 & $\mathrm{M}$ & 73 & 29 & 361 & 2190 & 1900 & 70 & 8 \\
\hline 13 & $\mathrm{~F}$ & 76 & 18 & 395 & 2300 & 2100 & 50 & 7 \\
\hline 14 & $\mathrm{~F}$ & 34 & 16 & 215 & 1570 & 1600 & 170 & 11 \\
\hline 15 & $\mathrm{~F}$ & 52 & 19 & 416 & 2350 & 2100 & 160 & 12 \\
\hline 16 & $\mathrm{M}$ & 74 & 14 & 503 & 1890 & 1900 & 250 & 16 \\
\hline 17 & $\mathrm{M}$ & 23 & 23 & 295 & 2000 & 2300 & 80 & 9 \\
\hline 18 & $\mathrm{M}$ & 41 & 52 & 431 & 2450 & 1800 & 170 & 9 \\
\hline 19 & $M$ & 23 & 36 & 258 & 1970 & 1500 & 155 & 12 \\
\hline 20 & $M$ & 29 & 34 & 267 & 1500 & 1700 & 190 & 14 \\
\hline 21 & $\mathrm{~F}$ & 46 & 58 & 251 & 1250 & 1000 & 60 & 11 \\
\hline 22 & $\mathrm{M}$ & 19 & 15 & 501 & 2070 & 1800 & 230 & 16 \\
\hline Mean & - & 45.5 & $28.4 \pm 3.4$ & $340.4 \pm 16.7$ & $2238.6 \pm 102.3$ & $1995.5 \pm 93.3$ & $155.2 \pm 15.8$ & $11.2 \pm 0.6$ \\
\hline
\end{tabular}

M: Male, F: Female. 


\section{DISCUSSION}

Consecutive multi-segment thoracic tuberculosis is characterized by the formation of a large unabsorbable abscess and sequestrum or refractory sinus. The ideal strategy of thoracic spinal tuberculosis management should be to achieve debridement, deformity correction and stability reconstruction in one-stage. Nonetheless, a standardized surgical procedure is yet to be established. The controversial subject is whether the anterior or posterior approach should be adopted for debridement and instrumentation. Recently, several studies have investigated the optimal operative approach for the treatment of thoracic spinal tuberculosis. Liu et al.(8) suggested that the anterior-approach, posterior-approach and combined anterior and posterior approach could all effectively treat thoracic tuberculosis, with the anterior approach being more suited for serious vertebral collapse. Similar results were provided by Zeng et al.(17), indicating that the anterior approach should be limitedly applied for severe cervicothoracic tuberculosis. Nevertheless, other authors commented that the posterior approach was associated with more effective deformity correction, and less complications and mortality than the anterior approach $(2,5,21)$. Taken together, anterior and posterior instrumentation have their own surgical indications respectively and thus the selection of the surgical approach should be based on the specific requirements of different kinds of patients.

The most obvious advantage of the single-stage posterior approach for treating multi-level thoracic tuberculosis is

Table IV: The Information of Follow-up (Cobb's Angle, ESR, Follow-up Time (Months))

\begin{tabular}{|c|c|c|c|c|c|c|c|c|}
\hline \multirow{2}{*}{ No } & \multirow{2}{*}{ Seg } & \multicolumn{3}{|c|}{ Cobb's angle $\left({ }^{\circ}\right)$} & \multicolumn{3}{|c|}{ ESR (mm/h) } & \multirow{2}{*}{$\begin{array}{c}\text { Follow-up } \\
\text { Time (months) }\end{array}$} \\
\hline & & Pre & Post & Final & Pre & Post & Final & \\
\hline 1 & T7-9 & 55 & 17 & 21 & 46 & 16 & 11 & 54 \\
\hline 2 & T3-5 & 69 & 25 & 31 & 50 & 18 & 9 & 43 \\
\hline 3 & T2-4 & 51 & 19 & 26 & 81 & 28 & 15 & 87 \\
\hline 4 & T1-3 & 59 & 18 & 22 & 47 & 29 & 11 & 34 \\
\hline 5 & T11-L1 & 60 & 13 & 15 & 73 & 38 & 21 & 69 \\
\hline 6 & T8-12 & 62 & 21 & 27 & 67 & 17 & 10 & 82 \\
\hline 7 & T10-12 & 50 & 23 & 20 & 97 & 29 & 9 & 24 \\
\hline 8 & T5-7 & 57 & 24 & 29 & 87 & 31 & 7 & 31 \\
\hline 9 & T6-8 & 66 & 19 & 21 & 61 & 32 & 12 & 27 \\
\hline 10 & T4-6 & 70 & 25 & 23 & 84 & 37 & 19 & 19 \\
\hline 11 & $\mathrm{~T} 7-12$ & 60 & 20 & 22 & 65 & 27 & 21 & 34 \\
\hline 12 & T7-8 & 40 & 15 & 21 & 73 & 34 & 17 & 25 \\
\hline 13 & T6-7 & 59 & 21 & 23 & 56 & 32 & 19 & 31 \\
\hline 14 & T6-10 & 52 & 16 & 15 & 73 & 34 & 23 & 45 \\
\hline 15 & T6-8 & 98 & 25 & 35 & 69 & 32 & 15 & 34 \\
\hline 16 & T1-4 & 53 & 19 & 18 & 53 & 27 & 13 & 23 \\
\hline 17 & T1-3 & 59 & 23 & 20 & 65 & 21 & 16 & 108 \\
\hline 18 & T9-12 & 54 & 18 & 24 & 77 & 23 & 15 & 25 \\
\hline 19 & T3-6 & 58 & 21 & 19 & 51 & 24 & 20 & 49 \\
\hline 20 & T2-4 & 62 & 17 & 15 & 92 & 35 & 19 & 48 \\
\hline 21 & T6-8 & 57 & 18 & 12 & 69 & 26 & 15 & 36 \\
\hline 22 & T9-10 & 105 & 19 & 22 & 53 & 16 & 18 & 27 \\
\hline $\mathbf{M}$ & - & $61.6 \pm 3.1$ & $19.8 \pm 0.7$ & $21.9 \pm 1.2$ & $67.7 \pm 3.1$ & $27.5 \pm 1.4$ & $15.2 \pm 1.0$ & $43.4 \pm 5.0$ \\
\hline $\mathbf{p}$ & & & $p<0.00$ & & & $\mathrm{p}<0.0$ & & \\
\hline
\end{tabular}

Seg: Segment, Pre: Pre-operative, Post: Post-operative, Final: Final follow-up, M: Mean, ESR: Erythrocyte sedimentation rate, p: $p$ value. 

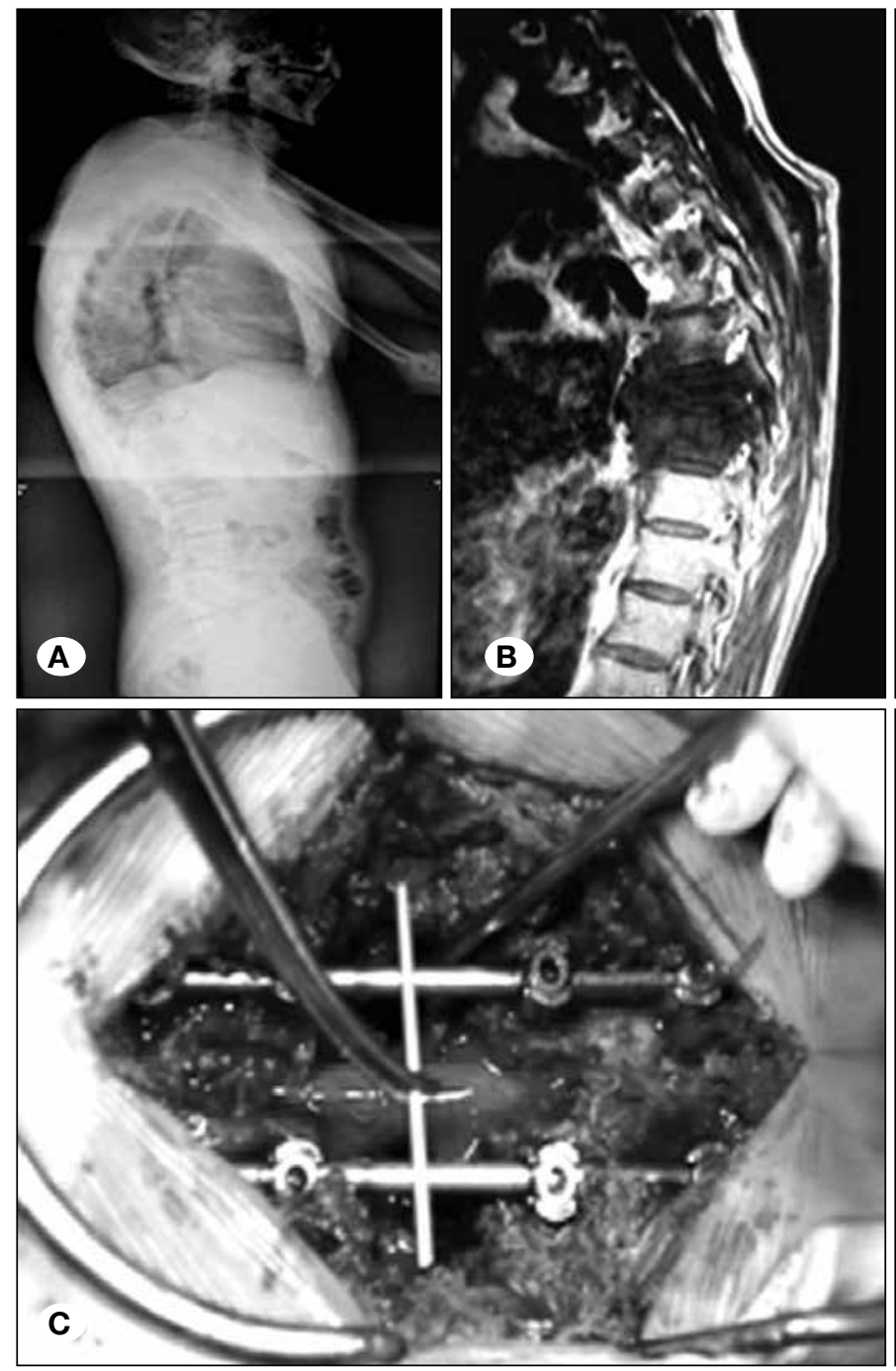

that it assists not only the debridement, decompression and bone graft simultaneously, but also maintains the stability of the spine after the removal of consecutive vertebrae. It has been reported that the single-stage posterior approach was effective for those patients who had an upper thoracic lesion, obvious kyphosis, deformities with neurological deficits due to the persistent spinal cord compression, and/or where conservative treatment and/or anterior instrumentation had failed (18-20). It is believed by Cui et al. (2) that the posterior approach also plays a better role than the anterior approach in maintaining the stability of the spine. While in the meantime, through a posterior insertion of structural bone graft, the loss of height resulting from absence of the anterior part of the vertebra can be corrected. Nonetheless, it is doubted by Shi et al. (14) whether a single posterior approach is suitable for foci involving more than two adjacent segments due to the difficulties in manipulation and the placement of instrumentation on the adjacent normal vertebrae. In our practice, laminectomy, facetectomy and pediculectomy were performed to assist kyphosis correction, and meanwhile provide an adequate operative space. The subsequent placement of
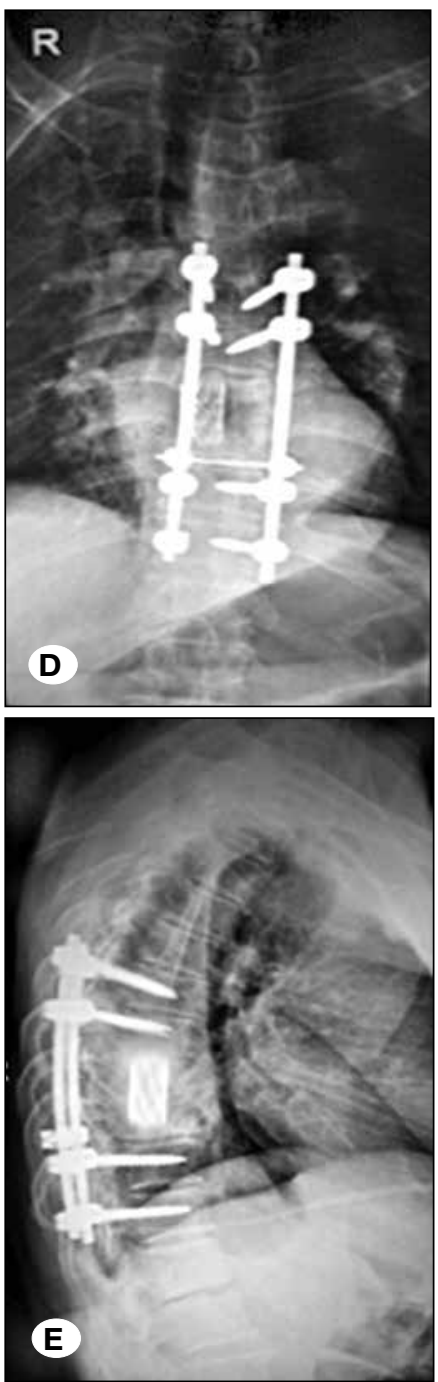

Figure 1: A 73-year-old male patient with T7-8 vertebral tuberculosis. He presented with back pain and paraplegia, with ASIA score C.

A, B) Preoperative lateral thoracic X-rays and sagittal MRI scan demonstrated the destruction of T7-8 vertebra with a kyphosis angle of $40^{\circ}$, and the formation of bilateral abscesses. C) The patient underwent one-stage posterior approach of debridement, drainage and internal fixation.

D, E) Cobb's angle was $15^{\circ}$ on the X-rays after surgery. The final AISA score was D. No recurrence was observed. internal fixation on the adjacent healthy vertebrae can further ensure the maintenance of kyphosis correction. Additionally, it may be questioned that the motion and function of the fixed segment would be sacrificed in the posterior-approach, thus leading to degeneration of neighboring segments. However, the thoracic spine does not require such a large range of motion as that in the lumbar column (16).

According to the results of previous reports and our experience in treating multi-level thoracic tuberculosis, the advantages of our single-stage posterior procedure can be summarized as follows:

1) Debridement, decompression, correction, and bone fusion can be achieved simultaneously, and thus the damage is minimized (14). Furthermore, some serious injuries that have occurred with the anterior approach can be avoided, including sternotomy, cutting of the diaphragm or injury to the vital organs and large vessels/segmental vessels, and the following complications, especially massive intraoperative bleeding. 
2) The placement of a tube can help the drainage of abscess and on the other hand, a pathway is provided for antituberculosis drug perfusion in the intervertebral space. As a result, the recurrence rate can be significantly reduced.

3) For patients who have developed a disability due to the kyphosis, the quality of anterior instrumentation is difficult to control, which may result in the loosening of internal fixation or loss of correction. Inversely, a posterior approach can effectually prevent the complications of the anterior approach and achieve stabilization so as to obviate the progression of the kyphotic deformity. In the series of $\mathrm{Ma}$ et al., the correction loss following anterior instrumentation was more than that following the posterior approach (11).

4) By placing instrumentation on the adjacent healthy vertebrae, the foci can be thoroughly isolated and removed in our procedure. Therefore, the incidence of recurrence is decreased.

5) This procedure can offer surgeons appropriate operative exposures to achieve decompression and correction of deformity, and insert a bone graft or bone graft with titanium mesh. Hence, excessive stretching of the spinal cord and other intraoperative complications can be avoided.

Based on our experience, the following issues should be noted to ensure the success of the surgery. Firstly, to avoid deterioration of neurological symptoms and deformity induced by excessive correction, the rod should be curved appropriately. Secondly, as a challenging procedure, the surgery treating thoracic kyphosis with spinal cord deficits might be too difficult to insert screws in the posterior approach. To address this problem, it will be helpful to resect part of superior or inferior vertebral plates. If the pedicles are small, hook and rod fixation is suitable to avert spinal cord injury induced by manual implantation of screws. Last but not least, operating carefully is of great importance, as it can prevent the abscess from breaking into the thoracic cavity. However, if the leakage of abscess into the thoracic cavity is sometimes inevitable, debridement with repeated irrigation using saline and iodine complex during operation is feasible. Postoperatively, application of closed thoracic drainage bag, anti-infection treatments, and also anti-tuberculosis agents will further facilitate the recovery of patients.

\section{- CONCLUSION}

The results of this study indicate that the one-stage posterior approach of debridement and drainage conform to the principles of the spinal tuberculosis treatment, and is viable for treating consecutive multi-level thoracic tuberculosis with kyphosis. It is feasible to prevent kyphosis through achieving debridement, decompression, stabilization, fusion, and correction simultaneously. However, our study has limited power due to its retrospective nature and small sample size. A prospective study with controlled variables may facilitate the comparison of the efficacy between different surgical modalities in the treatment of consecutive multi-segment thoracic tuberculosis with kyphosis.

\section{REFERENCES}

1. Assaghir $\mathrm{YM}$, Refae $\mathrm{HH}$, Alam-Eddin $\mathrm{M}$ : Anterior versus posterior debridement fusion for single-level dorsal tuberculosis: The role of graft-type and level of fixation on determining the outcome. Eur Spine J 25(12):3884-3893, 2016

2. Cui $X$, Ma YZ, Chen X, Cai XJ, Li HW, Bai YB: Outcomes of different surgical procedures in the treatment of spinal tuberculosis in adults. Med Princ Pract 22:346-350, 2013

3. Ekere AU, Yellowe BE, Echem RC: Conservative management of tuberculous spondylitis in a developing country. Niger $J$ Med 14:386-389, 2005

4. Ekinci S, Agilli M, Ersen O, Ekinci GH: Re.: Surgical strategy and management outcomes for adjacent multisegmental spinal tuberculosis. Spine (Phila Pa 1976) 40:E321, 2015

5. Garg B, Kandwal P, Nagaraja UB, Goswami A, Jayaswal A: Anterior versus posterior procedure for surgical treatment of thoracolumbar tuberculosis: A retrospective analysis. Indian J Orthop 46:165-170, 2012

6. Issack PS, Boachie-Adjei O: Surgical correction of kyphotic deformity in spinal tuberculosis. Int Orthop 36:353-357, 2012

7. Li L, Xu J, Ma Y, Tang D, Chen Y, Luo F, Li D, Hou T, Zhou $Q$, Dai $F, H e Q$, Zhang Z: Surgical strategy and management outcomes for adjacent multisegmental spinal tuberculosis: A retrospective study of forty-eight patients. Spine (Phila Pa 1976) 39:E40-E48, 2014

8. Liu P, Sun M, Li S, Wang Z, Ding G: A retrospective controlled study of three different operative approaches for the treatment of thoracic and lumbar spinal tuberculosis: Three years of follow-up. Clin Neurol Neurosurg 128:25-34, 2015

9. Liu Y, Chen Y, Yang L, Zhou X, Wang C, Qi M, Yuan W: The surgical treatment and related management for posttubercular kyphotic deformity of the cervical spine or the cervico-thoracic spine. Int Orthop 36:367-372, 2012

10. Luo F, Zhang ZH, Sun D, Xu JZ: One-stage anterior approach with arch plate to treat lumbosacral tuberculosis. Orthop Surg 7:354-358, 2015

11. Ma YZ, Cui X, Li HW, Chen X, Cai XJ, Bai YB: Outcomes of anterior and posterior instrumenta tion under different surgical procedures for treating thoracic and lumbar spinal tuberculosis in adults. Int Orthop 36:299-305, 2012

12. Moon MS, Moon YW, Moon JL, Kim SS, Sun DH: Conservative treatment of tuberculosis of the lumbar and lumbosacral spine. Clin Orthop Relat Res 398:40-49, 2002

13. Patankar AP: Tuberculosis of spine: An experience of 30 cases over two years. Asian J Neurosurg 11:226-231, 2016

14. Shi JD, Wang Q, Wang ZL: Primary issues in the selection of surgical procedures for thoracic and lumbar spinal tuberculosis. Orthop Surg 6:259-268, 2014

15. Tang MX, Zhang HQ, Wang YX, Guo CF, Liu JY: Treatment of spinal tuberculosis by debridement, interbody fusion and internal fixation via posterior approach only. Orthop Surg 8:89-93, 2016

16. Wang Z, Yuan H, Geng G, Shi J, Jin W: Posterior monosegmental fixation, combined with anterior debridement and strut graft, for treatment of the mono-segmental lumbar spine tuberculosis. Int Orthop 36:325-329, 2012 
17. Zeng H, Shen X, Luo C, Xu Z, Zhang Y, Liu Z, Wang X: Comparison of three surgical approaches for cervicothoracic spinal tuberculosis: A retrospective case-control study. J Orthop Surg Res 10: 100, 2015

18. Zhang H, Huang S, Guo H, Ge L, Sheng B, Wang Y, Guo C, Tang M: A clinical study of internal fixation, debridement and interbody thoracic fusion to treat thoracic tuberculosis via posterior approach only. Int Orthop 36:293-298, 2012

19. Zhang H, Sheng B, Tang M, Guo C, Liu S, Huang S, Gao Q, Liu J, Wu J: One-stage surgical treatment for upper thoracic spinal tuberculosis by internal fixation, debridement, and combined interbody and posterior fusion via posterior-only approach. Eur Spine J 22: 616-623, 2013
20. Zhang HQ, Li JS, Liu SH, Guo CF, Tang MX, Gao QL, Lin MZ, Yin $\mathrm{XH}$, Wang YX, Deng A: The use of posterior vertebral column resection in the management of severe posttuberculous kyphosis: A retrospective study and literature review. Arch Orthop Trauma Surg 133:1211-1218, 2013

21. Zhong W, Xiong G, Wang B, Lu C, Dai Z, Lv G: Surgical management for thoracic spinal tuberculosis posterior only versus anterior video-assisted thoracoscopic surgery. PLoS One 10:e119759, 2015 